\title{
A Lei no 9.099/1995 e O Sistema Criminal - Uma BusCa PELA EFICIÊNCIA
}

\author{
Luís Henrique Costa Ferreira \\ Polícia Civil do Estado da Bahia - Brasil
}

\author{
Daniel Pinheiro Mota da Silva ferreira \\ Universidade Federal da Bahia - Brasil
}

$$
\approx
$$

\begin{abstract}
RESUMO
A proposta deste trabalho foi avaliar os impactos das ocorrências referentes aos delitos absorvidos pela Lei n 9.099/1995 nas atividades de uma Delegacia de Polícia e buscar um modelo mais eficiente para o Estado lidar com eles. A Delegacia estudada foi a $2^{\mathrm{a}}$ DT $-2^{\mathrm{a}}$ Delegacia Territorial de Salvador, Estado da Bahia. O estudo fez uso da observação participativa para desenhar as etapas que compõe a lavratura de Termo Circunstanciado e, em seguida, estimar a demanda mensal do recurso tempo destinado a execução do procedimento pela cronometragem dos eventos. Após a análise dos dados, ficou demonstrado que o atual modelo, utilizado como padrão pelos Sistemas de Segurança Pública para o tratamento das ocorrências delituosas contidas na Lei № 9.099/1995, confronta o princípio da eficiência exibido na Constituição Federal. Ele impacta negativamente nas atividades de investigação criminal e atrasa a solução do conflito pela Justiça, ao criar uma instância administrativa desnecessária, na maioria das vezes. Ao final, foram apresentadas, dentre as muitas que possam ser enxergadas, duas possíveis soluções para o problema que despontaram dos elementos da pesquisa.
\end{abstract}

Palavras-Chave: Lei № 9.099/1995. Processo penal. Investigação criminal. Princípio da eficiência.

\section{INTRODUÇÃo}

No momento atual, a sociedade brasileira convive com assustadores índices de criminalidade. Segundo o Anuário Brasileiro de Segurança Pública ano 2014, a cada dez minutos, uma pessoa é assassinada no país. Essa conjuntura tem levado a debates que desembocaram em discussões sobre o atual modelo das Instituições do Sistema de Segurança Pública e, em especial, sobre as atividades das Polícias Judiciária e Militar. Com efeito, as Polícias estão sendo cobradas para se tornarem cada vez mais eficazes e eficientes nas suas 
atribuições constitucionais e legais. Mas nesse contexto, as Polícias Civis estão diariamente absorvendo uma quantidade impressionante de registros de ocorrências o que acaba por emperrar a capacidade de investigação criminal.

A Lei dos Juizados Especiais Criminais, Lei no 9.099/95, conforme se colhe da Exposição de Motivos do Projeto de Lei No 1.480-A, de 1989, foi concebida para atender aos preceitos do Artigo 98 da Constituição Federal e busca dar efetividade à norma penal, ao mesmo tempo em que privilegia os interesses da vítima, sem descuidar das garantias do devido processo legal. Em sua Exposição de Motivos, o citado Projeto de Lei foi explícito ao declarar que, entre suas linhas fundamentais, há a previsão do Procedimento Sumaríssimo nos seguintes termos: "não ocorrendo a imediata aplicação da pena restritiva de direitos ou multa, o Ministério Público formula oralmente a denúncia, se não houver necessidade de diligências imprescindíveis, ficando clara a dispensa do inquérito policial" (BRASIL, 1989). Ou seja, no seu espírito, a Lei optou pela dispensa do Inquérito Policial em prol da celeridade na solução do conflito, o que ficou expresso no artigo 69 do dispositivo legal, onde está estabelecido que "a autoridade policial que tomar conhecimento da ocorrência lavrará termo circunstanciado..." (BRASIL, 1995). O denominado Termo Circunstanciado de Ocorrência - TCO -, “... nada mais representa senão um boletim de ocorrência mais completo...” (TOURINHO FILHO, 2011, p. 92). O TCO deve conter a qualificação dos envolvidos e eventuais testemunhas, uma súmula das duas versões e o compromisso que as partes assumiram de comparecer perante o Juizado (TOURINHO FILHO, 2011).

Os Estados membros e o Distrito Federal trataram de implantar Juizados Especiais Civis e Criminais, com as pretensões de proporcionar ao cidadão: um acesso simples, célere e ágil a Justiça; mais um instrumento para atender a grande demanda por Justiça e liberar as Varas Comuns para as causas mais complexas. Os Juizados Especiais Criminais - JECRIM - possuem competência para a conciliação, o processo, o julgamento e a execução das infrações menores definidas no artigo 61, da Lei no 9.099/1995, com alteração introduzida pela Lei n 11.313/2006 (TOURINHO FILHO, 2011).

Quando se refere aos Juizados Especiais Criminais o Regimento Interno do Sistema dos Juizados Especiais do Estado, aprovado pelo Pleno do Tribunal de Justiça do Estado da Bahia e publicado no Diário do Poder Judiciário de 23 de agosto de 2007 como a Resolução No 12/2007 (Tribunal de Justiça do Estado da Bahia, 2015), estabelece: 
Art. 49. O procedimento no Juizado Especial Criminal será iniciado por uma das seguintes formas:

I. termo circunstanciado;

II. queixa prestada diretamente pela vitima ou por seu defensor;

III. expediente encaminhado pelo Ministério Público, polícia civil, militar ou rodoviária;

IV. Inquérito Policial remetido ao Juizado;

V. processo oriundo das Varas Criminais, na hipótese do art. $2^{\circ} \mathrm{da}$ Lei Federal no 10.259/01.

Parágrafo único. O termo circunstanciado, ou qualquer expediente a que se refere o caput deste artigo, será apresentado ao atendimento judiciário do Juizado Criminal, que providenciará, de logo, a designação de audiência preliminar, a intimação das partes, de seus respectivos advogados e do representante do Ministério Público, se presentes, ou a expedição dos competentes mandados (BAHIA, 2007).

O Manual dos Juizados Especiais Civis e Criminais do Tribunal de Justiça do Rio Grande do Norte, ao tratar do ingresso no Juizado Especial Criminal diretamente pelas partes, estabelece:

O Ministério Público, o ofendido ou o seu representante podem ajuizar peça informativa diretamente na Secretaria, desde que seja suficiente para sustentar a acusação, juntando documentos, se houver, elou indicando o rol de testemunhas e sua qualificação (Rio Grande do Norte, 2010, p. 25).

O pré-projeto do Manual de Procedimentos dos Juizados Especiais Criminais ${ }^{1}$, concebido pelo Conselho Nacional de Justiça na sua versão provisória, quando aborda a questão do conhecimento do fato pela autoridade policial, oferece as seguintes disposições:

$A$ autoridade policial, tanto a civil quanto a militar, tomando conhecimento de ocorrência que poderia, em tese, configurar infração penal de menor potencial ofensivo, lavrará o TCO (Termo Circunstanciado de Ocorrência) e o encaminhará imediatamente ao Juizado, juntamente com o réu e a vitima, providenciando-se as requisiçôes dos exames periciais necessários para realização de audiência preliminar.

Ao autor do fato que, após a lavratura do referido termo, for imediatamente encaminhado ao Juizado ou assumir o compromisso de a ele comparecer, não se imporá prisão em flagrante, nem se exigirá fiança.

1 Disponível em http://www.tjba.jus.br/fonaje/arquivos/manual_crime.pdf e em http://www.mp.ce. gov.br/orgaos/caocrim/manuais/manualjerim.pdf 
Nessa fase, em regra, não há oitiva da vítima, das testemunhas e interrogatório, devendo constar apenas o relato resumido dos fatos, bem como a indicação dos nomes e qualificação dos envolvidos (CNJ - Conselho Nacional de Justiça, 2009).

Na Cartilha dos Juizados Especiais Criminais, distribuída pelo Tribunal de Justiça do Estado do Rio de Janeiro, a questão "Como fazer para entrar com uma ação nos Juizados Especiais Criminais?” (Tribunal de Justiça do Rio de Janeiro) apresenta a seguinte solução:

O primeiro passo é procurar a delegacia mais próxima de onde ocorreu o fato. Lá será feito um Registro de Ocorrência. É o chamado $R O$. Se a delegacia se recusar a registrar a ocorrência ou houver demora no atendimento, o interessado deverá procurar diretamente $o$ Juizado da área. Se o crime for de ação privada (crimes $x$ a honra, exercício arbitrário das próprias razões) não basta ir à Delegacia. A ação só começa no Juizado, (Tribunal de Justiça do Rio de Janeiro).

A mesma resposta a questão anterior é oferecida pela cartilha correspondente divulgada pelo Tribunal de Justiça do Estado dede Goiás. Já o Tribunal de Justiça do Estado do Rio Grande do Sul, na Cartilha dos Juizados Especiais $^{2}$, ao tratar do acesso aos Juizados Especiais Criminais, apresenta a seguinte resposta a questão: $\mathrm{O}$ que é preciso fazer?

Basta registrar a ocorrência em uma delegacia de policia, apresentando carteira de identidade e dados pessoais como estado civil, profissão e endereço, ou se dirigir diretamente ao Juizado Criminal (confira endereços e horários de funcionamento em todo o Rio Grande do Sul no final da cartilha).

Se preferir, a vitima pode levar um advogado para auxiliar na conciliação ou solicitar a designação de um defensor público.

O Tribunal de Justiça Estado de Minas Gerais, em documento da série Conhecendo a Justiça, intitulado "Rapidez e Eficiência para Garantir Seu Direito: Juizados Especiais" ${ }^{3}$, ao responder a questão "Como os fatos chegam ao Juizado Criminal?", expõe o seguinte:

A infração é levada, primeiramente, ao conhecimento da Polícia Militar, que prepara o Boletim de Ocorrência (BO). Já o Termo Circunstanciado de Ocorrência (TCO) é um documento preparado

2 Disponível em https://www.tjrs.jus.br/site/poder_judiciario/comarcas/juizados_especiais/cartilha_ je.html?print $=$ true

3 Disponível em http://ftp.tjmg.jus.br/conhecendo/Juizados\%20Especiais.pdf 
pela Policia Civil e é o primeiro passo para se iniciar uma ação no Juizado Especial Criminal.

O Tribunal de Justiça do Estado do Amazonas, na Cartilha do Cidadão ${ }^{4}$, na página do site daquele Tribunal, ao tratar do ingresso no Juizado Especial Criminal, apresenta a seguinte resposta:

- Noticiando o fato junto à Delegacia. Esta lavra o Termo Circunstanciado de Ocorrência (TCO) e o encaminha aos Juizados Especiais Criminais;

- Apresentando petição (queixa ou reclamação) assinada por defensor habilitado.

Das informações acima, parece não haver impedimento para o interessado levar sua pretensão diretamente a um Juizado Especial Criminal, prescindível a lavratura do Termo Circunstanciado em uma Delegacia de Polícia como primeiro passo. A pretensão, desde o nascimento, tramitará perante o Juizado Especial Criminal e apenas se houver necessidade de diligências imprescindíveis a polícia judiciária deverá ser invocada. No entanto, as informações contidas nas cartilhas distribuídas pelos Tribunais de Justiça pesquisados parecem deixar em dúvida essa prerrogativa do interessado, levando a crer ser exigida a presença dele em uma Delegacia de Polícia para a lavratura do Termo Circunstanciado.

Nos casos específicos das Polícias Judiciárias Estaduais, as Polícias Civis, as atribuições principais delas estão descritas na Constituição Federal, no Artigo $144, \$ 4^{\circ}$, "as polícias civis, dirigidas por delegados de polícia de carreira, incumbem, ressalvada a competência da União, as funções de polícia judiciária e a apuração de infrações penais, exceto as militares" (BRASIL, 1988). A expressão Polícia Judiciária decorre da atuação como auxiliar do Poder Judiciário no desenvolvimento da persecução criminal e da responsabilidade em apurar a infração penal mediante o procedimento administrativo, denominado Inquérito Policial. Sendo assim, a responsabilidade primária da Polícia Judiciária é conduzir a investigação criminal, a qual consiste da atividade de pesquisa voltada para a elucidação de um fato criminoso (FERREIRA, 2013). O objetivo da investigação criminal é esclarecer o fato delituoso e determinar a autoria, e esse objetivo será atendido quando forem solucionadas as seguintes perguntas sobre o fato delituoso: Quem praticou o

4 Disponível em http://www.tjam.jus.br/index.php?option=com_content\&view=article\&id=824\&I temid $=206 \&$ limitstart $=5$ 
delito? Que meios ou instrumentos foram empregados? Que dano ou perigo produziu o delito? Quais os motivos determinaram o delito? De que modo o delito foi praticado? Em que local o delito foi praticado? Quando o delito foi praticado? (FERREIRA, 2013).

As situações, incluídas na Lei no 9.099/1995, chegam em grande quantidade as Delegacias de Polícia apesar de dispensarem, nos termos lei citada, qualquer espécie de investigação criminal. Essa realidade consome um recurso humano altamente especializado, o investigador criminal. $\mathrm{O}$ investigador criminal não é um profissional de treinamento rápido; investigação é uma atividade que, considerando os riscos, demanda além de aptidão, a aquisição de experiência prática demorada (FERREIRA, 2013). Porém, qualquer discussão sobre atividade policial não pode escapar do tema função social das instituições polícias. Monet observa sobre as funções da polícia o seguinte:

Entendemos por policia a primeira força, de natureza constitucional, destinada a assegurar a proteção dos direitos legais dos individuos". Por mais concisa que seja, a definição restitui perfeitamente as três dimensões da função policial às quais os cidadãos de hoje estão acostumados e que fazem da policia ao mesmo tempo uma função social, uma organização jurídica e um sistema de ação cujo recurso essencial é a força (MONET, 2006, p. 24).

Maria Tereza Sadek cita Maria Cândida Bahia ao se referir à função social da Polícia Civil do Estado da Bahia, observa:

$A$ análise do estilo de gestão das mulheres delegadas de polícia de Salvador, caracterizado como "gestão feminina", revelou o papel social da Polícia, até então enfatizado por sua função repressiva. A Delegacia é um departamento do Estado que, entre outras funções, presta serviços à população, geralmente carente, que recorre ao socorro policial - vitima de violência física, moral, étnica, sexual etc. (SADEK, Delegados de policia, 2009, p. 30).

Entre os agentes do sistema de justiça, o mais conbecido da população é o delegado de policia, menos por suas competências formais e mais por encontrar-se mais próximo do cotidiano do homem comum. Um respeito recheado de medo confere-lhe autoridade. Delegados, com frequência, sobretudo em cidades pequenas, extrapolam suas atribuiçôes, agem arbitrando conflitos, sendo procurados até mesmo para dissuadir a continuidade de disputas (SADEK, O sistema de justiça, 2010, p. 12).

Renato Sérgio de Lima comenta a função social da polícia como resultado das relações dinâmicas e combinatórias de três vetores: 
O trabalho policial na sociedade contemporânea caracteriza-se por um campo de forças sociais que se estrutura a partir de três posiçôes: o exercício da violência legítima, a construção do consenso e as práticas de excesso de poder, a violência ilegitima. As relaçôes dinâmicas e combinatórias desses três vetores vão definir a função social da organização policial na época contemporânea (LIMA, RATTON, \& AZEVEDO, 2014).

O Projeto de Lei - PL - No 5.117/2009, de autoria do deputado federal Regis de Oliveira, e o PL No 1.028/2011, do deputado federal João Campos, apresentam propostas similares para atribuir ao delegado de polícia competência para promover a conciliação, o julgamento e a execução de infrações sob o prisma da Lei No 9.099/95. O primeiro não evoluiu e foi arquivado, já o segundo está em tramitação. Os dois foram submetidos a manifestações contrárias, como a exposição da Secretaria de Comunicação Social da Procuradoria Geral da República (MPF, 2014) que cita a posição do Órgão assumida na audiência pública, realizada em 15 de julho de 2014, pela Comissão de Constituição, Justiça e Cidadania da Câmara dos Deputados, para discutir o PL 1.028/2011. Eis alguns dos argumentos do MPF:

O coordenador-adjunto da área criminal do gabinete do procurador-geral da República, destacou a importância das atividades desenvolvidas pela polícia para a investigação de crimes. No entanto, defendeu que a possibilidade de mediação de acordos civis não deve ser feita pela autoridade policial. $O$ acordo deve ser livre e o ambiente policial não cria condiçôes psíquicas para isso, nem é propicio ao diálogo, sustentou (MPF, 2014).

O PL No 5.117/2009 apresentou entre suas justificativas (BRASIL, 2009):

Essa atuação comunitária da Polícia Civil possibilitará a redução do crescente volume de feitos dos cartórios dos fóruns (JECRIM), o que refletirá diretamente sobre a tempestividade da prestação jurisdicional, resgatando não apenas a sensação subjetiva de segurança do cidadão, mas principalmente o seu sentimento de realização da justiça.

Inicialmente, mais de 60\% das ocorrências policiais estavam inseridas na esfera da Lei $n^{\circ}$ 9.099/95, mas o rol de delitos de menor potencial ofensivo foi ampliado pela Lei $n^{\circ} 10.259 / 01$, e, posteriormente, a Lei $n^{\circ}$. 9.099/95 foi alterada pela Lei $n^{\circ}$ 11.313/06.

A grande vantagem deste projeto éo baixo custo para a sua implantação, pois os recursos humanos e materiais necessários já estão disponiveis nas delegacias de policia. 
De outra parte, são inúmeros os benefícios dessa medida, entre eles, se destacam: os ganhos sociais decorrentes da melhoria da qualidade de atendimento à comunidade; o reforço da auto-estima do policial envolvido nas conciliaçôes, mediante a reconhecida relevância de sua nova função; a celeridade e economia processual que nortearão o trâmite dos termos circunstanciados nos fóruns, cujos cartórios reduzirão os volumes de feitos relativos aos delitos de menor potencial ofensivos.

2011):

O PL No 1.028/2011 apresentou entre suas justificativas (BRASIL,

A proposta em tela, que possibilita a composição preliminar dos danos oriundos de conflitos decorrentes dos crimes de menor potencial ofensivo pelos delegados de polícia, foi inspirada no projeto de lei $n^{\circ}$ 5.117/2009, de autoria do ex-deputado Regis de Oliveira, que versa sobre a mesma matéria.

Atualmente, evidencia-se um crescente aumento no numero de feitos nos cartórios dos fóruns referentes aos delitos de menor potencial ofensivo, impossibilitando o cumprimento dos princípios idealizados pelo legislador, principalmente, os da celeridade e da economia processual, gerando resultados que não correspondem aos anseios das partes e da comunidade, no que tange à tempestividade, aumentando a sensação de impunidade não só para a população ordeira, mas também para a marginalidade.

A Constituição Federal, em seu artigo 37, estabelece que a "administração pública direta e indireta de qualquer dos Poderes da União, dos Estados, do Distrito Federal e dos Municípios obedecerá aos princípios de legalidade, impessoalidade, moralidade, publicidade e eficiência” (BRASIL, 1988). Para Ronaldo Dias, "eficiência é conceito juridicamente indeterminado, entendendo-se como tal, conceito cujo conteúdo e extensão, na seara do Direito, em larga medida é incerto" (DIAS, 2004, p. 55). A interpretação corrente do princípio da eficiência fica bem expressa nas palavras de Augustinho Palula ao citar que "esse princípio impõe à Administração Pública, direta e indireta, e a seus agentes, a persecução do bem comum e a adoção dos critérios legais e morais necessários para a melhor utilização possível dos recursos públicos de maneira a evitarem-se desperdícios e garantir-se maior rentabilidade social" (PALULA, 2010, p. 26).

A proposta deste trabalho foi avaliar os impactos das Ocorrências referentes aos delitos absorvidos pela Lei no 9.099/1995 nas atividades de uma 
Delegacia de Polícia e buscar um modelo mais eficiente para o Estado lidar com eles. A Delegacia estudada foi a 2a DT - Delegacia Territorial de Salvador, Estado da Bahia. O estudo fez uso da observação participativa para desenhar as etapas que compõe a lavratura de Termo Circunstanciado - TCO e estimar o tempo e os recursos empregados no procedimento. Após a análise dos dados, ficou demonstrado que o atual modelo, utilizado como padrão pelos Sistemas de Segurança Pública para o tratamento das ocorrências delituosas contidas na Lei № 9.099/1995, confronta o principio da eficiência exibido na Constituição Federal. Ele impacta negativamente nas atividades de investigação criminal e atrasa a solução do conflito pela Justiça, ao criar uma instância administrativa desnecessária, na maioria das vezes.

Ao final, foram apresentadas, dentre as muitas que possam ser enxergadas, duas possíveis soluçôes para o problema que despontaram dos elementos da pesquisa.

\section{Procedimento Metodológico}

O presente estudo envolveu pesquisas de observação participativa e quali-quant, na 2a Delegacia Territorial, no Município de Salvador, Estado da Bahia. Para isso foram três as atividades desenvolvidas:

2.1 Estudo dos registros de ocorrências - BO -;

2.2 Estudo do procedimento de lavratura do Termo Circunstanciado - TCO -;

2.3 Estimativa do recurso tempo despendido para as lavraturas dos TCOs.

\section{I ESTUdo dos Registros de OCORRÊnCIAS}

Esta atividade consistiu na análise estatística dos registros de ocorrências lançados no banco de dados da $2^{\mathrm{a}} \mathrm{DT}$. Por questão de operacionalidade da pesquisa, a população estudada ficou limitada às ocorrências catalogadas nos seguintes tipos penais: Ameaça, calúnia, difamação e injúria. Todas as categorias representam tipos penais que, na forma básica, estão sob a égide da Lei dos Juizados Especiais Criminais - Lei No 9.099/2015. Pelos mesmos motivos, o período da pesquisa ficou restrito ao intervalo fechado entre os anos 2010 e 2014. 
Um Termo Circunstanciado é lavrado nas seguintes situações:

a) Quando uma pessoa, no geral um policial, apresenta um conduzido na delegacia detido por algum motivo;

b) Quando o interessado comparece à delegacia para comunicar um delito mediante o registro de um boletim de ocorrência BO. A depender das informaçóes contidas no $\mathrm{BO}$ pode ser necessária investigação criminal ou não. Apenas os boletins de ocorrências gerados diretamente pelo interessado e no qual não haja a apresentação de um conduzido interessa a esta pesquisa.

c) Nos termos dos artigos $5^{\circ}$ e $6^{\circ}$ do Código de Processo Penal.

O período estudado compreendeu os anos de 2010 até 2014, o resumo dos dados está na Tabela 1 :

\begin{tabular}{|c|c|c|c|c|c|}
\hline \multicolumn{5}{|c|}{ Tabela 1: TOTAL DE OCORRÊNCIAS REGISTRADAS (BO) } \\
\hline Ano & Total de Ocorrências & Ameaça & Calúnia & Difamação & Injúria \\
\hline 2014 & 5.368 & 704 & 53 & 58 & 59 \\
\hline 2013 & 4.853 & 737 & 46 & 108 & 67 \\
\hline 2012 & 5.090 & 876 & 31 & 137 & 38 \\
\hline 2011 & 5.884 & 1.190 & 53 & 147 & 49 \\
\hline 2010 & 5.969 & 1.257 & 73 & 196 & 57 \\
\hline
\end{tabular}

Fonte: Os autores

Os dados foram estudados mensalmente e para verificar a presença de outliers $^{5}$ para cada um dos quatro conjuntos de dados foram construídos Gráficos BoxPlote. O valor 31, referente a quantidade de registros de delito de difamação no mês de setembro do ano de 2010, se destacou como sendo um outlier no conjunto do tipo penal difamação. O tratamento ao dado fora da curva foi a retirada dele do conjunto. As médias mensais das ocorrências registradas como ameaça, calúnia, difamação e injúria foram calculadas nos os valores de 79, 4, 10 e 5, respectivamente. O somatório destas estatísticas foi escolhido como estimador da média total de ocorrências mensais de ameaça, calúnia, difamação e injúria, a qual será:

Média $=79+4+10+5=98$ (somatório das médias mensais das ocorrências de ameaça, calúnia, difamação e injúria).

5 Valor aberrante, atípico e que destoa por demais dos outros valores da série. 
Logo o montante de 98 ocorrências por mês é a média mensal do somatório das ocorrências de ameaça, calúnia, difamação e injúria. Essa quantidade representa $21,60 \%$ do valor de 448 , que é a média mensal do total de ocorrências paras os anos estudados.

O passo seguinte foi estimar a quantidade de ocorrências tipificadas como ameaça, calúnia, difamação ou injúria que antes de serem submetidas ao Poder Judiciário necessitam ter elementos esclarecidos e exijam a realização de investigação criminal. Estão enquadradas nessa classificação as situações, entre outras, nas quais a autoria é desconhecida. Foram consideradas situações nas quais a autoria é conhecida as que se assemelhassem aos seguintes modelos extraídos dos dados reais ${ }^{6}$ :

\section{BO 1}

"FULANO DE TAL compareceu nesta unidade informando que seu vizinho SICRANO DE TAL, residente na XXXXXXXXXX, vem tirando o sossego de todos onde mora, o mesmo profere palavras de baixo calão e desrespeita a todos. Na data citada o comunicante teria chamado a atenção dele e por esse motivo foi ameaçado de morte".

\section{BO 2}

"Compareceu a esta unidade policial a comunicante supra citada informando que seu vizinho SICRANO DE TAL, ambos residentes na XXXXXXXXX, a agrediu verbalmente Xingando-a de velha vagabunda e também ameaçou atear fogo no carro da queixosa".

Com o propósito de simplificar a pesquisa, a População estudada ficou limitada ao ano de 2014, com 874 Ocorrências (Tabela 1), escolhido por ser o mais próximo da atualidade. $\mathrm{O}$ erro foi estabelecido em $5 \%$ e o tamanho da amostra, calculado de maneira simplificada ${ }^{7}$ foi de 274 amostras $^{8}$. Nessas 274 amostras ${ }^{9}$ foram encontrados 9 (nove) registros relacionados a ameaça e difamação que exigem a realização de investigação criminal e que representam 3,28\% da amostragem. Reproduzindo essa situação para a média mensal surge que:

6 Dados que permitissem a identificação das pessoas envolvidas foram omitidos dos exemplos.

7 Fórmula: $\mathrm{n}=\left[\mathrm{Nx}\left(1 / \varepsilon^{\wedge} 2\right)\right] /\left[\mathrm{N}+\left(1 / \varepsilon^{\wedge} 2\right)\right]$, onde: $\mathrm{n}$ é o tamanho da amostragem; $\mathrm{N}$ é o tamanho da população; $\varepsilon$ é o erro.

$8 \mathrm{n}=\left[874 \mathrm{x}\left(1 / 0,05^{\wedge} 2\right)\right] /\left[874+\left(1 / 0,05^{\wedge} 2\right)\right]=274$ amostras

9 As amostras foram colhidas aleatoriamente, sem reposição, mediante sorteio da posição no registro do banco de dados de Boletins de Ocorrências sem distinção da tipificação atribuída ao fato, desde que seja de ameaça, ou calúnia, ou difamação, ou injúria. Para o sorteio foi utilizado o gerador de número randômicos do aplicativo MSExcel. 
a) $3,28 \% \times 98=3,21$, representa a quantidade média mensal de Ocorrências de injúria, calúnia, ameaça, ou difamação, que irá depender de investigação criminal.

b) 98-3,21=94,79, representa a quantidade média mensal de Ocorrências de injúria, calúnia, ameaça, ou difamação que irá gerar Termo Circunstanciado sem necessidade de investigação criminal.

\subsection{O Procedimento de Lavratura do Termo Circuns- TANCIADO - TCO}

Nesta fase, o objetivo foi identificar as etapas que compõem o procedimento de lavratura de um Termo Circunstanciado a fim de que fosse possível estimar os recursos empregados para obtenção do produto final. $\mathrm{O}$ método utilizado foi a observação participativa e permitiu a identificação das seguintes etapas:

\begin{tabular}{|c|c|c|}
\hline ETAPA & DESCRIÇÃO & $\begin{array}{c}\text { PESSOAL } \\
\text { ENVOLVIDO }\end{array}$ \\
\hline $\begin{array}{l}\text { 1) Registro do bo- } \\
\text { letim de ocorrência } \\
\text { - } \mathrm{BO}\end{array}$ & $\begin{array}{l}\text { O interessado comparece à delegacia e efetua } \\
\text { a comunicação do suposto fato típico para } \\
\text { acionar o Estado para apurá-lo. }\end{array}$ & $\begin{array}{l}\text { Policial que proce- } \\
\text { de o registro do } \mathrm{BO}\end{array}$ \\
\hline $\begin{array}{l}\text { 2) Análise do bole- } \\
\text { tim de ocorrência }\end{array}$ & $\begin{array}{l}\text { O Delegado de Polícia analisa o BO e deter- } \\
\text { mina as diligências preliminares, nos casos } \\
\text { avaliados as intimações do interessado e do } \\
\text { suposto autor. }\end{array}$ & $\begin{array}{l}\text { Delegado de Po- } \\
\text { lícia e Escrivão de } \\
\text { Polícia. }\end{array}$ \\
\hline $\begin{array}{l}\text { 3) Realização das } \\
\text { intimações e de- } \\
\text { mais diligências }\end{array}$ & $\begin{array}{l}\text { Equipes de investigadores efetuam as intima- } \\
\text { ções determinadas }\end{array}$ & Investigadores \\
\hline $\begin{array}{l}\text { 4) Realização das } \\
\text { audiências e lavra- } \\
\text { tura do TCO }\end{array}$ & $\begin{array}{l}\text { Presentes o interessado (que passa a ser } \\
\text { denominado comunicante) e o suposto autor } \\
\text { (que passa a ser denominado comunicado) } \\
\text { são colhidas as versões de cada um para os } \\
\text { fatos e os respectivos compromissos. O TCO } \\
\text { é lavrado. }\end{array}$ & $\begin{array}{l}\text { Delegado de Po- } \\
\text { lícia e Escrivão de } \\
\text { Polícia. }\end{array}$ \\
\hline $\begin{array}{l}\text { 5) Registro do } \\
\text { TCO e remessa do } \\
\text { procedimento para } \\
\text { o Juizado Especial } \\
\text { Criminal }\end{array}$ & $\begin{array}{l}\text { O TCO é autuado e remetido para Juizado } \\
\text { Especial Criminal. }\end{array}$ & $\begin{array}{l}\text { Escrivão e Investi- } \\
\text { gadores }\end{array}$ \\
\hline
\end{tabular}

Fonte: Autor 


\subsection{Estimativa do Recurso Tempo Despendido para as LAVRATURAS DOS TCOS.}

Detalhadas as etapas percorridas para a lavratura, a tarefa se voltou para a apropriação dos recursos absorvidos na atividade. Após a análise das etapas ficou identificado que, com os recursos disponíveis para a pesquisa, as únicas etapas suscetíveis de controle e isolamento são o "Registro do boletim de ocorrência - BO" e a "Realização das audiências e lavratura do TCO”. As demais etapas são facilmente contaminadas pela execução de múltiplas tarefas correlatas e, portanto, demandariam maior investimento na pesquisa. Diante da complexidade exigida, optou-se por apropriar apenas o recurso tempo empregado na atividade "Realização das audiências e lavratura do TCO".

O método utilizado para apropriar o tempo consumido na etapa selecionada foi a cronometragem de 50 Termos Circunstanciados lavrados pelo pesquisador na condição de Delegado de Polícia Civil durante os anos de 2014 e 2015. A Tabela 2 apresenta os resultados das cronometragens.

\begin{tabular}{|c|c|c|c|}
\hline \multicolumn{5}{|c|}{ Tabela 2: CRONOMETRAGEM } \\
\hline Medição & Minutos Decimais & Medição & Minutos Decimais \\
\hline 1 & 33,000000 & 26 & 40,0002 \\
\hline 2 & 40,000000 & 27 & 53,0002 \\
\hline 3 & 33,000167 & 28 & 45,0000 \\
\hline 4 & 40,000000 & 29 & 44,0000 \\
\hline 5 & 51,000000 & 30 & 36,0000 \\
\hline 6 & 49,000000 & 31 & 37,0000 \\
\hline 7 & 52,000167 & 32 & 40,0000 \\
\hline 8 & 32,000000 & 33 & 39,0002 \\
\hline 9 & 33,000167 & 34 & 43,0002 \\
\hline 10 & 43,000167 & 35 & 35,0000 \\
\hline 11 & 52,000167 & 36 & 40,0002 \\
\hline 12 & 40,000000 & 37 & 38,0000 \\
\hline 13 & 45,000000 & 38 & 40,0000 \\
\hline 14 & 45,000167 & 39 & 27,0002 \\
\hline 15 & 38,000000 & 40 & 48,0000 \\
\hline 16 & 38,000000 & 41 & 37,0002 \\
\hline 17 & 46,000167 & 42 & 50,0002 \\
\hline 18 & 46,000167 & 43 & 35,0000 \\
\hline
\end{tabular}




\begin{tabular}{|c|c|c|c|}
\hline \multicolumn{4}{|c|}{ Tabela 2: CRONOMETRAGEM } \\
\hline Medição & Minutos Decimais & Medição & Minutos Decimais \\
\hline 19 & 44,000000 & 44 & 39,0000 \\
\hline 20 & 29,000000 & 45 & 50,0002 \\
\hline 21 & 48,000167 & 46 & 31,0002 \\
\hline 22 & 37,000000 & 47 & 47,0000 \\
\hline 23 & 39,000167 & 48 & 38,0000 \\
\hline 24 & 36,000000 & 49 & 48,0002 \\
\hline 25 & 38,000000 & 50 & 38,0000 \\
\hline
\end{tabular}

Fonte: Autor

A média das amostras foi calculada como sendo 40,90007 minutos decimais, que convertidos ficaram em 40 $57^{\prime \prime}$ ( 40 minutos e cinquenta e sete segundos) aproximados. Este é o recurso tempo consumido por TCO na execução da etapa "Realização das audiências e lavratura do TCO". Logo, considerando 94,79 registros por mês os tempos despendidos para um mês e para um ano com a tarefa citada são de aproximados:

a) $\quad 8$ (oito) dias ${ }^{10}$ aproximados por mês.

b) 97 (noventa e sete) dias ${ }^{11}$ aproximados por ano.

Os dados expõem que 97 dias de trabalho na delegacia são utilizados em audiências para elaborações de $\mathrm{TCO}(s)$ relativos aos delitos de calúnia, difamação, injúria e ameaça sem que ocorra qualquer investigação criminal. Significa que mais de 3 meses de tempo de serviço por ano são consumidos apenas nas audiências para a lavratura dos $\mathrm{TCO}(\mathrm{s})$ pesquisados.

As observações participativas e as demais pesquisas levaram também a identificar outros detalhes, decorrentes dessas situações, que causam algum um tipo de desconforto social, são eles:

a) $\mathrm{O}$ interessado registra o $\mathrm{BO}$, aguarda o agendamento da audiência, presta declarações e assiste o TCO ser lavrado. É informado que a peça será remetida ao Poder Judiciário e que deve aguardar ser citado. Posteriormente diante da demora de efeito efetivo o interessado retorna à delegacia reclamando que os problemas continuam. Ele exige uma ação imediata da Polícia

10 Considerando oito horas de trabalho por dia.

11 Considerando oito horas de trabalho por dia. 
Civil para cessar o problema, só que essa exigência deve ser demandada ao Poder Judiciário. A Delegacia de Polícia representou um atraso na chegada do problema ao Judiciário.

b) As cartilhas pesquisadas, elaboradas por diversos Tribunais de Justiça, independente das características da demanda, induzem o interessado a dirigir-se a uma Delegacia de Polícia para, depois de lavrado o TCO, ter acesso ao Juizado Especial Criminal. Fica assim induzida uma instância administrativa não necessariamente obrigatória.

c) Muitas vezes os demandantes buscam a conciliação, só que a Delegacia de Polícia não possui prerrogativa para conduzir uma conciliação.

d) A cultura e as condições econômicas da comunidade muito influenciam na demanda por TCO de ameaça, injúria, difamação e calúnia. Percebe-se que os bairros ditos como populares geram maior demanda.

e) Muitas das demandas com as características pesquisadas envolvem vizinhos de residências.

f) Nem todos os registros de ocorrência que se enquadram na seleção da pesquisa irão gerar TCO, alguns serão atingidos pelos critérios de seleção informal citados na Exposição de Motivos da Lei $n^{\circ}$ 9.099/1995.

Na prática, operam diversos critérios de seleção informais e politicamente caóticos, inclusive entre os órgãos de persecução penal e judiciais. Não se desconhece que, em elevadíssima percentagem de certos crimes de ação penal pública, a polícia não instaura o inquérito, e o Ministério Público e o Juiz atuam de modo a que se atinja a prescrição (BRASIL, 1989).

\section{Considerações Parciais}

É interessante expor as conclusões avaliando possíveis críticas aos resultados:

a) O tempo despendido para realização de audiências para a lavratura de TCO pode variar consideravelmente em função do delegado de polícia presidente da apuração e do escrivão. $\mathrm{Na}$ 
pesquisa foi avaliado apenas o tempo de um delegado de polícia e de um escrivão especificamente.

b) A média de boletins que necessitavam de investigação criminal para a lavratura do TCO foi obtida considerando uma amostra extraída do ano de 2014. Talvez o valor esteja mais bem representado se fosse proveniente de uma amostragem extraída de todos os anos selecionados para a pesquisa, considerados como conglomerados.

c) Não há como afirmar que os valores das médias e tempo possam ser extrapolados para todas as Delegacias de Polícia. Espera-se que fatores como a realidade social da comunidade cliente poderá influenciar nesses dados e modificar as relações entre eles.

d) Não foram avaliados os recursos de tempos despendidos para todas as etapas da lavratura de um TCO.

No entanto, como pesquisa exploratória, o trabalho cumpriu o objetivo: demonstrar que o atual modelo de tratamento das ocorrências delituosas contidas na Lei no 9.099/1995, utilizado como padrão pelo Sistema de Segurança Pública, confronta com o princípio da eficiência exibido na Constituição Federal. O modelo de tratamento citado remete para as Polícias Judiciárias uma quantidade significativa de conflitos que independem de qualquer espécie de investigação criminal impedindo-os de serem apreciados diretamente pelo Poder Judiciário. Essa demanda chega às Delegacias na forma de registros de Boletins de Ocorrências sobre infrações penais de menor potencial ofensivo e que irão gerar Termos Circunstanciados sem dar origem a uma única ordem de serviço para investigar autoria, ou qualquer circunstância do suposto delito.

Nas situações pesquisadas, presentes os interessados, a Delegacia de Polícia apenas reduz as declarações e compromissos a termos e depois remete o TCO para o Juizado Especial Criminal. Nada é acrescentado de atividade policial investigativa, e a Delegacia realiza uma tarefa compatível com a de um atendente judiciário (BAHIA, 1997).

A passagem das situações estudadas pela Delegacia de Polícia, ao invés de serem propostas diretamente em um Juizado Especial Criminal, apenas representa um elemento de atraso na solução da demanda diante do uso de uma instância administrativa desnecessária. As normas consultadas indicam que não há impedimentos para o interessado levar a demanda pessoalmente a um 
Juizado Especial Criminal, o que importa é que no Juizado haja estrutura para atendê-lo. Também é possível que a demanda levada diretamente ao Juizado pelo interessado seja, depois de avaliada pelo Ministério Público e pelo o Juiz, remetida para uma Delegacia de Polícia para diligências essenciais. Nesse contexto, surgem situações nas quais profissionais treinados para solucionar delitos se encontram efetuando atividades que não necessitam de investigações. Justo quando a demanda por esses nunca esteve tão elevada. Assim, Investigadores, Escrivães e Delegados de Polícia passam a dedicar pelo menos um quarto do tempo anual com problemas, que em termos policiais, já se apresentam solucionados. Com certeza, esses profissionais seriam melhores utilizados se estivessem trabalhando nas soluções de homicídios e roubos, por exemplo.

Contra as conclusões acima, pode ser arguida a chamada função social da polícia, a qual prega atuar não só na investigação do delito, mas também na prevenção; e que, para tanto, não pode recusar o contato com o cidadão e o conhecimento do conflito social. Particularmente consideramos essa atribuição inerente a todos os integrantes do Sistema de Segurança Pública e não há o porquê de impô-la e cobrá-la só das polícias. Ainda mais, consideradas as polêmicas em torno dos PL(s) no 5.117/2009 e n ${ }^{\circ}$ 1.028/2011.

Logo, após a análise dos dados, ficou demonstrado que o atual modelo, utilizado como padrão pelos Sistemas de Segurança Pública para o tratamento das ocorrências delituosas contidas na Lei no 9.099/1995, confronta o principio da eficiência exibido na Constituição Federal. Ele impacta negativamente nas atividades de investigação criminal e atrasa a solução do conflito pela Justiça, ao criar uma instância administrativa desnecessária, na maioria das vezes. Não se trata aqui de defender obstáculos para o cidadão registra o BO na Delegacia de Polícia; mas, sim, deixar evidente para ele que não há a necessidade de incluir a etapa policial na lide e que ela pode ser levada diretamente ao Poder Judiciário, para assim, em tese, ser mais célere. Entres as muitas possíveis soluções para o problema apresentado, duas surgem dos elementos observados: a) produzir campanhas para conscientizar o interessado a conduzir a demanda diretamente para o Juizado Especial Criminal, sem tramitar em uma Delegacia de Polícia, e preparar as estruturas físicas, humanas e normativas dos Juizados para absorverem esse serviço; ou b) conduzir as discussões no sentido de possibilitar que as demandas se encerrem diretamente na Delegacia de Polícia, sem ter que tramitar no Juizado Especial Criminal. As viabilidades destas duas soluções fogem aos limites deste trabalho e demandam estudos específicos. 


\title{
Luís Henrique Costa ferreira
}

Mestre em Segurança Pública Justiça e Cidadania, Delegado de Polícia Civil do Estado da Bahia; Engenheiro Civil e

Matemático.

E-MAIL:AMARO.AJBG@DPF.GOV.BR

Daniel Pinheiro Mota da Silva ferreira

Graduando em Direito - UfBA.

E-MAIL: AMARO.AJBG@DPF.GOV.BR

\section{The LaW No 9.099/1995 ANd The CRiminal System - A QUEST FOR EFFICIENCY}

\begin{abstract}
The purpose of this study was to evaluate the impacts of occurrences relating to offenses absorbed by Law No. 9,099 / 1995 in the activities of a Police Station and to seek a more efficient model for the State to deal with. The Police Station studied was the 2a DT in Salvador, State of Bahia. The study made use of participant observation to design the steps that comprise the drawing of the Circumstantiated Term and then estimate the monthly demand of the resource time destined to the execution of the procedure by the timing of the events. After analyzing the data, it was demonstrated that the current model, used as standard by the Public Security Systems for the treatment of criminal occurrences contained in Law, confronts the principle of efficiency established in the Federal Constitution. It impacts negatively on criminal investigation and slows down the decision of the conflict by the courts by creating an unnecessary administrative instance most of the time. At the end, two possible solutions to the problem that emerged from the research elements were presented, among the many that can be seen.
\end{abstract}

KEYwORDS: Law No.9,099/95. Criminal process. Criminal investigation. Principle of efficiency.

\section{La Ley No 9.099/1995 y el Sistema Criminal - UNA BÚSQUEDA POR LA EFICIENCIA}

\section{RESUMEN}

El propósito de este estudio es evaluar el impacto de los eventos relacionados con los delitos absorbidos por la Ley n 9.099/1995 en las actividades de una Comisaría de Policía, además de buscar un modelo más eficiente para el Estado tratar de ellos. La Policía estudiada fue la $2^{\mathrm{a}}$ DT - $2^{\mathrm{a}}$ Delegacia Territorial Policial, en Salvador, Estado de Bahia. El estudio hizo uso de la observación participtiva para diseñar las etapas que componen la labranza de um Termo Circusntanciado 
y, a continuación, estimar la demanda mensual del recurso tiempo destinado a la ejecución del procedimento por el cronometraje de los eventos. Después de analizar los datos se determinó que el modelo actual, utilizado como estándar por el Sistema Brasilero de Seguridad Pública para la Ley n ${ }^{\circ}$ 9.099/1995, contraria al principio de eficiencia que si muestra en la Constitución Federal. Él tiene impacto negativo en las actividades de investigación criminal y retrasa la solución del conflicto por los tribunales. Exhibimos también dos posibles soluciones al problema encontrado.

Palabras Clave: Ley no 9.099/1995. Los procesos penales. Investigación criminal. Principio de eficiencia.

\section{REFERÊNCIAS}

ANUÁRIO Brasileiro de Segurança Pública ano 2014. (1 de outubro de 2015).http://www.mpma.mp.br/arquivos/CAOPCEAP/8o_anuario_ brasileiro_de_seguranca_publica.pdf. Fonte: Ministério Público do Estado do Maranhão: http://www.mpma.mp.br/arquivos/ CAOPCEAP/8o_anuario_brasileiro_de_seguranca_publica.pdf

AZEVEDO, R. G. (outubro de 2001). Juizados Esepciais Criminais: Uma abordagem sociológica sobre a informalização da justiça penal no Brasil. Revista Brasileira de Ciências Sociais, 16(47), 97-182.

BAHIA. (1997). Lei No 7.033/1997. Salvador: Estado da Bahia.

BAHIA. (2007). Resolução No 12/2007 - TJBA - Aprova o regimento interno dos juizados especiais do Estado da Bahia. Salvador: TJBA.

BRASIL. (1988). Constituição Federal. Brasilia: Brasil.

BRASIL. (1989). PL No 1.480-A, de 1989. Brasília: Câmara dos Deputados.

BRASIL. (1995). Lei No 9.099/1995. Brasília: Brasil.

BRASIL. (2009). PL No 5.117/2009. Brasília: Câmara dos Deputados.

BRASIL. (2011). PL 1.028/2011. Brasília: Câmara dos Deputados.

CNJ - Conselho Nacional de Justiça. (2009). Manual de procedimentos do juizados especiais criminais. Brasília: CNJ.

DIAS, R. B. (2004). Responsabilidade do Estado pela função jurisdicional. Belo Horizonte: Del Rey.

FERREIRA, L. H. (2013). Investigação criminal : um estudo metodológico (2 ed.). São Paulo: Sicureza. 
LIMA, R. S., RATTON, J. L., \& AZEVEDO, R. G. (2014). Crime, polícia e justiça no Brasil. São Paulo: Contexto.

MONET, J.-C. (2006). Polícias e sociedade na Europa. São Paulo: EDUSP.

MPF. (15 de jul de 2014). Notícias. Fonte: Ministério Público Federal: http://noticias.pgr.mpf.mp.br/noticias/noticias-do-site/copy_ of_criminal/audiencia-discute-projeto-de-lei-que-transfere-paradelegado-conciliacao-de-crimes-menos-graves

PALULA, A. V. (2010). Administração pública: teoria e questões. Rio de Janeiro: Elsivier.

PIANALTO DE AZEVEDO, E. (28 de fevereiro de 2001). Juizado Especial Criminal: As promessas de Construção e a realidade construída na Comarca de Chapecó -1996/2000. Dissertação de Mestrado em Direito. Universidade Federal de Santa Catarina. Acesso em 1 de agosto de 2015, disponível em Repositório Institucional da UFSC: https://repositorio. ufsc.br/bitstream/handle/123456789/79977/178516.pdf ?sequence=1

PINHEIRO, F. D. (2007). Juizado Especial Criminal: do modelo consensual à radicalização da função simbólico do sistema penal. Dissertação submetida à Universidade Federal de Santa Catarina - UFSC para a obtenção do título de Mestre em Direito, Universidade Federal de Santa Catarina, Centro de Ciências Jurídicas.

Rio Grande do Norte. (2010). Manual expresso dos juizados especiais cíveis e criminais TJRN. Natal: TJRN.

SADEK, M. T. (2009). Delegados de polícia. Rio de Janeiro: Centro Edelsten de Pesquisas Sociais.

SADEK, M. T. (2010). O sistema de justiça. Rio de Janeiro: Centro Edelstein de Pesquisas Sociais.

TJAM. (2009). Cartilha do Cidadão (JE Cíveis e Criminais - Capital) - 3 Juizados Especiais Criminais. Fonte: Tribunal de Justiça do Estado do Amazonas: http://www.tjam.jus.br/index.php?option=com_content \&view $=$ article $\&$ id $=824 \&$ Itemid $=583 \&$ limitstart $=5$

TJGO. (2015). Juizados Especiais Criminais. Fonte: Tribunal de Justiça do Estado de Goias: http://docs.tjgo.jus.br/comarcas/juizadosespeciais/ diversos/DOC_cartilhacriminal.pdf

TOURINHO FILHO, F. d. (2011). Comentários à lei dos juizados especiais criminais ( $8^{a}$ ed.). São Paulo, SP, Brasil: Saraiva. 
Tribunal de Justiça de Minas Gerais. (2010). Rapidez e eficiência para garantir seu direito : Juizados Especiais. Belo Horizonte: TJMG.

Tribunal de Justiça do Estado da Bahia. (2015 de outubro de 2015).

Regimento interno dos juizados especiais civeis e criminais do estado da Bahia. Fonte: Tribunal de Justiça do Estado da Bahia: www. tj.ba.gov.br/secao/juizados/regimento_juizados.pdf

Tribunal de Justiça do Estado do Ceara. (2000). Manual de Procedimentos dos Juizados Cíveis e Criminais - TJCE. Fortaleza: TJCE.

Tribunal de Justiça do Estado do Mato Grosso. (2015). Como funcionam os juizados especiais. Cuiba: TJMT.

Tribunal de Justiça do Estado do Rio Grande do Sul. (2009). Cartilha dos Juizados Especiais. Porto Alegre: TJRS.

Tribunal de Justiça do Rio de Janeiro. (s.d.). Cartilha dos Juizados Especiais Criminais. Rio de Janeiro: TJRJ.

WAISELFISZ, J. J. (2014). Mapa da Violência. Fonte: Mapa da Violência: http://www.mapadaviolencia.org.br/. 
